\title{
La foto-provocación como método. Su aplicación en un estudio de la autonomía en personas con diagnóstico de Trastorno Mental Severo
}

\author{
Photo-elicitation as Method. Its Application in a Study About \\ Autonomy in People with Several Mental Illness Diagnose
}

\author{
FELIPE CORREDOR-ÁLVAREZ \\ Universidad Autónoma de Barcelona \\ fellipecorr@gmail.com (ESPAÑA) \\ LUPICINIO ÍNIGUEZ-RUEDA
}

Universidad Autónoma de Barcelona (ESPAÑA)

Recibido: 14.032016
Aceptado: 07.09 .2016

\section{RESUMEN}

El uso de la fotografía como parte de la metodología en las ciencias sociales ha ganado un creciente reconocimiento, tanto por sus posibilidades técnicometodológicas, como por las posibilidades de nuevas maneras de implicación entre investigadores y participantes. Una modalidad importante ha sido la fotoprovocación (photo-elicitation), que combina fotografías y entrevista. Presentamos la adaptación de este método — sus bases, aplicación y análisis- en una investigación sobre la autonomía en el contexto de la inserción laboral de personas diagnosticadas con trastorno mental severo. Fue combinada con la Observación participante puntual (OPP), una breve inmersión en el campo para conocer en primera persona el contexto investigado manteniendo el registro de diario de campo. Presentamos un contexto a la foto-provocación y la OPP, incluyendo antecedentes y una discusión sobre sus posibilidades, el papel de la fotografía en la entrevista y cómo se da la provocación, de la mano de Roland Barthes.

En la segunda parte del artículo, presentaremos la aplicación de este dispositivo metodológico. En el diseño se detallarán las sucesivas decisiones metodológicas, que concluyen en el uso de una cámara digital que se rotan entre ocho participantes, y observación participante puntual con tres de ellos. El material 
recolectado es analizado por medio del análisis temático de contenido: la creación de categorías a partir de la lectura y relectura (y escucha) de las entrevistas, que permite la flexibilidad necesaria para trabajar con entrevistas, fotografías y diario de campo, pues el mejor análisis de las fotografías, en este contexto, es el que pasa por las palabras de sus participantes. Finalizamos con una discusión sobre los alcances de esta mezcla de técnicas y su análisis, que, en síntesis, permite presentar una mirada personal de la cotidianidad laboral, que más adelante permitirá fomentar una colaboración en la interpretación, a la vez que hace la entrevista más dinámica y fluida.

\title{
PALABRAS CLAVE
}

Foto-provocación; Observación participante puntual; Fotografía como método; Análisis de imagen; Inserción laboral

\begin{abstract}
The use of photography as part of the methodology in Social Sciences has gained a growing recognition, not only for its technic-methodologic possibilities, but also for the possibilities in new ways of implication between researchers and participants. Photo-elicitation has raised as an important modality, combining photography and interviews. We present the adaptation of this method - basis, application and analysis - in a research about autonomy in the context of labor inclusion of people diagnosed with Severe Mental Illness. Photo-elicitation was combined with Isolated Participant Observation (IPO), a brief immersion on the field to know in first-hand the context researched, keeping registry in the field notebook. We present a context to photo-elicitation and IPO, including background and discussion of its possibilities, the role of photography in the interview and how elicitation raises, following Roland Barthes work.

In the second part of the paper we present the application of this methodological device. In the section of design, we explain the followed methodological decisions, concluding in the use of a digital camera used by eight participants, and IPO with three of them. Data were analyzed by thematic content analysis: creation of categories by reading and re-reading (and listening) of interviews, which allows enough flexibility to work with interviews, photographs and field notebook, since the best analysis of photography is the one mixed with the words of the participants, in this context. We finalize with a discussion about the reaches of this mix of technics and its analysis, which allows to promote a personal look in the everyday labor life, which will allow to promote a collaboration in interpretation, while makes the interview more dynamic and fluid
\end{abstract}




\section{KEY WORDS}

Photo-elicitation; Isolated Participant Observation; Photography as Method; Image Analysis; Labor inclusion

\section{INTRODUCCIÓN}

En el marco de la metodología cualitativa, en las últimas décadas los métodos visuales han experimentado un auge importante, por ejemplo, por el giro cultural desarrollado en las ciencias sociales a partir de la década de los setenta, destacando la centralidad de lo visual en las culturas occidentales, en parte gracias al desarrollo de las tecnologías de representación visual y su aplicación a las ciencias sociales (Rose, 2001), así como el ánimo posmoderno de descentrar la autoridad del investigador (Harper, 2002). A nivel metodológico, podemos señalar también las limitaciones de los métodos basados en palabras que empujan a explorar nuevas modalidades, además de poder permitir diferentes acercamientos a los fenómenos sociales a investigar y a los mismos participantes (Johnson, 2012).

La metodología cualitativa suele contar con una serie de sensibilidades que le son particulares, a saber: sensibilidad histórica, es decir, entender los antecedentes del fenómeno como frutos de un devenir; una sensibilidad cultural, en la que el contexto intersubjetivo y el sistema de normas específicas juegan un papel fundamental; una sensibilidad socio-política, que tiene que ver con una constante reflexión explícita sobre las posibles consecuencias políticas que afecten el camino del cambio social, y una sensibilidad contextual (Íñiguez, 2004).

Justamente por estas características de la metodología cualitativa, en una reciente investigación sobre la autonomía y la vida laboral de personas diagnosticadas con Trastorno Mental Severo (TMS), utilizamos un método cualitativo con imágenes, palabras y observación. Las dos primeras —imágenes y palabras - son parte del método de foto-provocación, que se compone de dos estadios: el primero, una toma de fotografías por parte de los participantes voluntarios del CET (Centre Especial de Treball, explicado más adelante), y el segundo, una entrevista con base en estas fotografías, complementado con un guión de entrevista. La observación se compone de lo que hemos denominado la Observación participante puntual (OPP): una breve inmersión en el campo para poder conocer en primera persona el contexto investigado y registro de diario de campo, que se diferencia de la observación participante clásica, especialmente por no preocuparse por la saturación, ya que ésta se alcanza con el conjunto de técnicas, no por la observación participante en sí.

El objetivo de este artículo es presentar el método de la foto-provocación y su funcionamiento a nivel operativo, metodológico y teórico, junto la observación participante puntual, para luego mostrar su pertinencia ilustrándolo con algunos resultados de la investigación mencionada. La inclusión de

EMPIRIA. Revista de Metodología de Ciencias Sociales. N. ${ }^{o}$ 35, septiembre - diciembre, 2016, pp. 175-204. ISSN: 1139-5737, DOI/empiria.35.2016.17173 
resultados es breve - a manera de ejemplificación — dadas las limitaciones del mismo formato del artículo y no presentamos el análisis ni las conclusiones de la investigación, pues el foco de este trabajo es cien por cien metodológico. Como parte del análisis de la foto-provocación, explicaremos los antecedentes del uso de fotografías en la investigación en ciencias sociales y parte de sus actuales avances. También reflexionaremos sobre el proceso mismo de la provocación en la situación de entrevista de la mano de Roland Barthes y su libro La cámara lúcida (1999). En la segunda parte del artículo, presentaremos la aplicación de este dispositivo metodológico. En el diseño se detallarán las sucesivas decisiones metodológicas, que concluyen en el uso de una cámara digital que se rotan entre ocho participantes, y observación participante puntual con tres de ellos.

El material recolectado es analizado por medio del análisis temático de contenido: la creación de categorías a partir de la lectura y relectura (y escucha) de las entrevistas, que permite la flexibilidad necesaria para trabajar con entrevistas, fotografías y diario de campo, pues el mejor análisis de las fotografías, en este contexto, es el que pasa por las palabras de sus participantes.

\section{LA CONSTRUCCIÓN DEL DISPOSITIVO METODOLÓGICO: IMÁGENES, PALABRAS Y PRESENCIA}

Las técnicas que nos proponemos utilizar son, en un primer momento, la toma de fotografías hechas por usuarios de servicios de empleo protegido y, en base a estas imágenes, entrevistas con las que obtendremos el material textual para posteriormente analizar.

Esta secuencia de técnicas es conocida en el mundo de la investigación cualitativa anglosajona como photo-elicitation, y será traducido como fotoprovocación ${ }^{1}$.

A las imágenes y las palabras se añadirá la presencia misma. Realizamos sesiones breves de observación participante puntual, con su respectivo registro de diario de campo. Las imágenes, las palabras y la presencia serán explicadas en las próximas páginas, junto con su procedimiento.

\subsection{Imágenes}

Desde la antropología, y bajo la necesidad de documentar de diferentes formas la vida en culturas lejanas y diferentes para el investigador, se ha utilizado tradicionalmente el registro de video o audiovisual (Grbich, 1999).

1 El diccionario panhispánico de dudas considera la palabra "elicitación” (Real Academia Española, 2005) una adaptación innecesaria del verbo en inglés to elicit, que aparece en los textos de psicología. Esta misma fuente recomienda en su lugar el uso de "provocar", "suscitar" u "obtener", según los casos. De estas opciones, la más acertada es provocar (Real Academia Española, s/f), ajustándose al sentido de sus acepciones 1 y 8 del diccionario de la Real Academia: "Incitar, inducir a alguien a que ejecute algo" (s/f, párr. 1); "Facilitar, ayudar" (s/f, párr. 8). 
El primer acercamiento debidamente justificado a la fotografía como metodología en las ciencias sociales fue hecho por los antropólogos Mead y Bateson en los años 30 (1942, citados por Banks, 2007), como un complemento de la observación participante durante un estudio en Samoa y Nueva Guinea. El uso de las fotografías estaba influenciado por el lingüista y antropólogo Edward Sapir y de la psicología Gestalt. Entendiendo los elementos de la cultura como un todo - de igual manera que la personalidad entendida por la corriente Gestalt- el estudio de la socialización de los niños permite observar la transmisión y adquisición de tal personalidad. Las imágenes, para ellos, actuaron como una manera de acceder a aquello que no se puede decir con palabras, "la relación intangible entre tipos diferentes de comportamiento estandarizado por la cultura" (Bateson \& Mead, 1942: xii, citado por Banks, 2007: 29, traducción propia) Uno de los limitantes de la incursión de la fotografía en algunas ciencias sociales era el auge del positivismo y los métodos cuantitativos, cuya naturaleza no dejaba mucha cabida al análisis visual. En el momento en el que la interpretación se retoma como instrumento en las ciencias sociales es cuando la fotografía encuentra su espacio de acción. Es por esto, quizás, que desde un principio tuvo una importante cabida en la antropología, disciplina que estuvo menos influenciada por el ímpetu positivista.

El uso de la fotografía como base de entrevistas se remonta a mediados del siglo pasado. El antropólogo Collier (1957) nombró foto-entrevista a este proceso de presentar fotografías en una entrevista para una investigación. Al sentir limitaciones utilizando la entrevista tradicional, Collier y su equipo decidieron utilizar fotografías en el proceso de entrevista, y comparando la experiencia con cuestiones propias de la entrevista tradicional, encontraron particularidades de este híbrido.

Su investigación giraba en torno a los niveles de estrés de las personas en las provincias marítimas de Canadá. En estas zonas, hubo procesos de cambio dados por la inmersión de fábricas y las nuevas formas de trabajo que implican, sumadas a la convivencia con nuevos vecinos de diferentes etnias. Collier y sus colaboradores utilizaron fotografías antiguas y recientes de los lugares implicados en el proceso de entrevista.

El equipo de investigadores consideró que las fotos se ceñían a la memoria de las personas y así evitaba malentendidos. Su principal ventaja, de alguna forma, era que daba a las entrevistas una representación más fiel de la realidad, ya que recogían datos más precisos y comprensivos, estimulaban la memoria, así como las declaraciones emocionales de la vida de las personas. Estas ventajas observadas están en la línea de la herencia del pensamiento positivista. Otra característica relevante descrita por el equipo es que con esta técnica se evitaba la fatiga de las entrevistas.

A pesar de las ventajas listadas en estas primeras experiencias, las técnicas que utilizan fotografías en las entrevistas no tuvieron mayor auge en los años venideros. Fue a partir de finales de la década de los 70 cuando recientes desarrollos en las ciencias sociales dieron paso a una aceptación mayor de las entrevistas con fotos; desarrollos como el ánimo postmoderno de descentrar la 
autoridad del investigador (Harper, 2002).

El uso de fotografías en el proceso investigador o interventivo ha sido diverso, dependiendo de los objetivos de las fotografías, quién las toma, a quién son enseñadas, cómo son presentadas, etc. Ejemplos de ello son: photoelicitation, photo-feedback, photovoice, photo-novella y photo-essay.

Foto-provocación (photo-elicitation) es una técnica en la que se desarrollan entrevistas utilizando fotos para provocar (elicit) respuestas sobre la temática a tratar (Hurworth, Clark, Martin, \& Thomsen, 2005). Ha tenido una creciente aceptación entre psicólogos críticos interesados en una experiencia encarnada (enbodied) (Johnson, 2012), además de abrir a los participantes e investigadores a novedosas maneras de experiencia, más allá de la pesada mono-modalidad de las aproximaciones tradicionales en la investigación cualitativa. El centro del análisis apunta tanto a las imágenes como al texto (Johnson, 2009; Suchar, 1997). Su temática de investigación puede ser muy variada, destacando estudios con niños y jóvenes, por ejemplo en Bolton, Pole y Mizen (2001) y Epstein, Stevens, McKeever y Baruchel (2006), así como con temas de salud mental (Johnson, 2009, 2012; Radley, Hodgetts, \& Cullen, 2005). Photo-elicitation es la forma más genérica de llamar a las entrevistas guiadas por fotografías.

Sampson-Cordle (citado por Harper, 2002) en su tesis doctoral llamó photofeedback a la técnica en la que los entrevistados eran los mismos fotógrafos. Sin embargo, nosotros preferimos mantener la nominación de foto-provocación para mantener el énfasis en el proceso. Otra técnica relativa es photo-novella: se trata de contar una historia sobre la cotidianidad a través de fotos, como una herramienta de activismo y cambio político con el ánimo de hacer ver a quienes toman decisiones políticas las realidades menos visibles (Wang \& Burris, 1994). Photovoice es una técnica vinculada a la IAP (Investigación-AcciónParticipación) y prácticas transformadoras, con énfasis en la participación y empoderamiento de personas marginadas (Johnson, 2012). Se trata de que la gente captura y discute sobre las fotografías para así buscar cambios sociales - por medio de la misma discusión crítica de las situaciones que aquejan a la gente-, y algunos de ellos podrían optar por defender el cambio en sus comunidades (Wang, 1999). La sutil diferencia entre photovoice y photo-novella es que la segunda pretende necesariamente contar una historia, y la primera no. Estas técnicas no tienen un especial enfoque en el producto textual (Johnson, 2009).

La forma en la que nosotros hemos aplicado la técnica no se ciñe estrictamente a ninguna de las experiencias revisadas y mencionadas, como ser verá más adelante. Además, realizamos un acompañamiento a manera de observación participante puntual a algunas de las personas. Sin embargo, optamos por mantener la nominación de foto-provocación para preservar el énfasis en el proceso de producción. 


\subsubsection{Las fotos y la provocación}

El objetivo de este apartado es presentar algunas reflexiones sobre el funcionamiento en sí de la técnica de la foto-provocación —cómo interactúan las personas y las fotografías — mas no de su análisis, que será explicado páginas más adelante en el apartado "Procedimiento de análisis".

En nuestra opinión, para que realmente resulte informativo, el material producido en el trabajo de campo debe tener ciertas características: provocar, despertar reflexión.

Para nombrar las características de las fotos que provocan, primero debe hablarse de las fotos que no provocan. En sus investigaciones, Harper (2002) encontró que algunas fotos que usaba no despertaban mayores reflexiones en los entrevistados. Se trataba de fotos hechas por él mismo, y descubrió que el problema es que eran demasiado familiares para los entrevistados, por ejemplo, estaban hechas en su sitio de trabajo, a la altura de los ojos, siendo una toma muy repetitiva y familiar para ellos. Entonces, decidió cambiar la toma, buscando imágenes que rompieran esquemas, $-\mathrm{o}$, como mínimo, evidenciaran la ignorancia del investigador - invitando a explicar cosas que ellos daban por hecho. En términos de perspectiva, una de las fotos fue a los dedos de un mecánico haciendo su trabajo. En otro caso, utilizó una fotografía aérea de una granja, para entrevistar a los granjeros. También utilizó fotos antiguas de la misma granja: lo que les era familiar, les fue presentado de manera no familiar. Así, esta extrañeza de la cotidianidad actúa como una suerte de desencadenante de la provocación misma.

En la búsqueda de un entendimiento más profundo de la fotografía y de su particular papel mediador en la interacción entre las personas, y de las personas con ella misma, indagamos en el libro La cámara lúcida de Roland Barthes (1999). El autor se aventura a un desciframiento en carne propia de el qué de la fotografía, yendo más allá de las clasificaciones formales y los aspectos meramente técnicos. La lectura de este libro despertó numerosas reflexiones sobre la fotografía en sí y sobre su aplicación en la investigación.

La fotografía, según Barthes, se compone de "tres prácticas (o de tres emociones, o de tres intenciones): hacer, experimentar, mirar" (Barthes, 1999: 35). También se pueden distinguir tres elementos necesarios que hacen parte de la misma fotografía: el Operator, quien toma la foto; el Spectator, quien la ve, a veces quien la consume; y el blanco del objetivo, aquello o aquél que es fotografiado, al que llama Spectrum, ya que, al mismo tiempo, hace referencia al carácter de espectáculo y lo relativo a la muerte, retorno instantáneo a lo muerto, pues de alguna manera la fotografía es un pequeño parto, el nacimiento de un objeto que muere rápidamente, en la medida en que fue algo cuya existencia no se repite, ya no es.

En la fotografía más espontánea, como la amateur, en la que salen personas, difícil es que el Spectrum o el Operator calculen el resultado total del producto que está a punto de crearse. Las sensaciones que pueda despertar ese objeto sólo pueden conocerse a posteriori y justo en el momento de observación. 
Dichas sensaciones o reacciones al objeto-producto podrían moverse entre lo que Roland Barthes denomina como el Studium y el Punctum.

El interés que puede despertar la fotografía, el Studium, es diferente al "estudio", ya que el Studium es "la aplicación a una cosa, el gusto por alguien, una suerte de dedicación general, ciertamente afanosa, pero sin agudeza especial" (Barthes, 1999: 58). El punctum, por su parte, trata de eso de la fotografía que viene a buscarnos. Al mismo tiempo es un pinchazo, una herida; y una puntuación, salpicado por puntos, el estar salpicado es también causalidad. "El Punctum de una foto es ese azar que en ella me despunta (pero que también me lastima, me punza)." (Barthes, 1999: 59, cursivas del original).

Así, son características del punctum, no sólo el hecho de ejercer una fuerte atracción, sino también punzar, incluso herir al Spectator, y llevarlo más allá de lo que se puede poner en la foto. Otro rasgo importante de este impacto es que es personal, una misma foto puede resultar sólo "interesante" o despertar un Studium para alguien, y ser sumamente punzante para otra persona.

La fotografía tiene una relación particular con el tiempo. Remite a un pasado, se referencia deícticamente, no se puede desvincular de aquello que señala. Posee un carácter tautológico: "en la fotografía una pipa es siempre una pipa" (Barthes, 1999: 30). Sin embargo, ese señalamiento ocurre en el presente, otorgándole un estatus de realidad al pasado. Es una realidad tan efímera como el tiempo de apertura del obturador, muere tan pronto como éste se cierra; ese cruce de circunstancias (que es la fotografía) muere tan pronto como nace. La referencia es tan sólo a escasos milisegundos.

Por lo tanto, no es el pasado lo que hay en esa foto, esta realidad es un señalamiento, algo que ocurre - y que se (re)construye cada vez- en el presente. Este proceso de muerte prematura es el mismo proceso de objetivación (en el sentido de hacer-objeto-de) de aquello retratado; durante esos milisegundos el sujeto pasa a ser un objeto a referenciar: "Imaginariamente, la Fotografía (aquélla que está en mi intención) representa ese momento tan sutil en que, a decir verdad, no soy ni sujeto ni objeto, sino más bien un sujeto que se siente devenir de objeto" (Barthes, 1999: 42, cursivas del original) Entonces se trata de una microexperiencia de la muerte, el momento en el que uno es espectro (Spectrum), el otro me despropia de uno mismo. A partir de ahí ese nuevo objeto puede ser interpretado, pensado o analizado. Podríamos extender por analogía esta reflexión a otras técnicas de recogida de información en la investigación, como la entrevista u observación participante: se llega a hacer de las personas un objeto a analizar. En el caso de la foto-provocación ese objeto visual creado pasa también por la interpretación de la misma persona que lo creó en la entrevista posterior a la toma de fotografías.

La técnica de foto-provocación lo que busca es precisamente eso, hacer hablar sobre las fotografías, aunque se pueda tratar de unas palabras insuficientes para lo vasta que pueda ser una imagen, pero sumamente relevantes como técnica en el proceso de investigación y dinamizadora de la práctica social que es la entrevista. 
En la situación de foto-provocación se da un proceso de animación mutua:

En este sombrío desierto, tal foto, de golpe, me llega a mis manos; me anima y yo la animo. Es así, pues, como debo nombrar la atracción que la hace existir: una animación. La foto, de por sí, no es animada (yo no creo en las fotos «vivientes»), pero me anima: es lo que hace toda aventura. (Barthes, 1999: 55, cursivas del original).

Estas palabras resultan bastante reveladoras para dar cuenta de la misma provocación (elicitation) en la situación de entrevista. La persona entrevistada es al mismo tiempo Operator y Spectator, y en ocasiones, Spectrum. Así, la persona se sitúa frente a aquello que, en su momento, desde su ojo y con su dedo quiso objetizar; los píxeles que señalan aquél cruce de circunstancias. El entrevistador y el participante conversan sobre el significado, las sensaciones, describen su Studium o intentar dar cuenta de su Punctum, se negocian significados. En ese proceso, la fotografía le anima, y él anima a su vez la fotografía. El investigador anima de otra forma al entrevistado - con preguntas, comentarios, impresiones-, éste reanima la foto, ésta lo reanima a él y se habla sobre la imagen, la cotidianidad. Esto es entonces una forma de describir la provocación.

La perspectiva de Barthes permite dar luces sobre la mecánica del proceso de la foto-provocación, desde el momento en el que se planifica la fotografía y se caracterizan los roles respecto a la misma. Es diferente, en múltiples niveles, si la fotografía es hecha por el investigador o por el entrevistado. Si la fotografía la hace el investigador la fotografía, en el fondo, no sería más que un anexo al guión de entrevista que también lleva a cabo el investigador. En cambio, dado que es el entrevistado quien hace las fotografías, con instrucciones ambiguas, su mirada cobra agencia que repercute en los resultados y demás fases de la investigación. En el momento de la entrevista, tras haber hecho las fotos y haber recibido instrucciones sobre la temática, intuye de qué se trata la entrevista y facilita su dinámica.

Así, las caracterizaciones de Barthes permiten clasificar los diferentes elementos del proceso de planificación y sobre todo de apreciación de la fotografía y su discusión, dando cuenta de cómo se despliega la interacción, no sólo a nivel de rapport, sino también de la animación mutua en la explicación de los elementos de la fotografía, y, especialmente, su significado.

\subsection{Palabras}

El papel de la fotografía en la entrevista no es, pues, un intermediario sino un mediador, en el sentido latouriano. Un intermediario es aquello -un objeto, una persona, un puesto, una entidad o un entramado... un ente que en la Teoría de Actor-Red se conoce como actante (Latour, 2001) — cuya función es facilitar o vehicular significados o propósitos sin transformación alguna: los 
datos de entrada (input) definen los datos de salida (output). Su papel se limita a establecer una conexión o un vínculo entre sujetos, un sujeto y un objeto, un propósito y un medio... un actante y otro actante. Muchas tecnologías cotidianas han devenido en intermediarios, como los microondas o las lavadoras (cuando funcionan bien y son fáciles de manejar) (Latour, 2001; 2008, en Corredor Tirado e Íñiguez, 2010). La fotografía no es un papel -o un conjunto de píxeles-que representan tal cual una realidad que se transmite de un momento $A$ a un momento $B$; o una idea tal cual de una cabeza $A$ a una cabeza $B$.

La fotografía es, en cambio, un mediador. Los mediadores se caracterizan por intervenir en las conexiones entre los elementos, es decir, propician acción en la asociación. Es un acontecimiento en sí mismo, ni causa ni fin, se trata de un estar en medio (Latour, 2001). Como mediadora que es, la fotografía transforma, distorsiona o modifica el significado de los elementos que supuestamente carga, excediendo así el acto mismo de su intervención en la asociación de elementos, en el caso que nos ocupa, la situación social —el entramado semióticomaterial- que es la entrevista de foto-provocación.

Así, el significado que le damos a la fotografía es puramente relacional. Becker (Citado por Bonetto, 2016), señala que toda fotografía debe ser considerada siempre en contexto. Juan Soto (2012: 223) indica que las imágenes "guardan relaciones estrechas con los marcos sociales y temporales donde aparecen. Nunca son independientes de los observadores"; dichos marcos se invisibilizan, naturalizando así la ilusión de objetividad de las imágenes. Las claves del desciframiento de las imágenes están justamente en la relación, mas no en las imágenes mismas, y esta relación la estudiamos a partir de las palabras que provocan las fotografías y la entrevista en sí.

En este sentido, la investigación con fotografías permite una profundidad especial en la interacción con el otro, ya que, como dice Harper: "Mi entusiasmo por la foto-provocación además se da por la colaboración que esta técnica inspira. Cuando dos o más personas discuten el significado de las fotografías, intentan descifrar algo juntos. Esto es, creo, un modelo ideal de investigación" (Harper, 2002: 23, traducción propia). Esta colaboración en el desciframiento de la fotografía es un efecto social que se da en la misma práctica de la discusión.

El tipo de entrevista que proponemos para la foto-provocación está basada en la entrevista individual semiestructurada. Como es sabido, la entrevista es deudora del giro linguístico, que, desde la filosofía, planteaba la necesidad de "una aproximación linguiística a los problemas filosóficos, sobre la base de que gran parte de los mismos se disuelven si se comprende mejor el uso que se hace del lenguaje" (Rorty, 1990, citado en Fabra \& Domènech, 2001: 21), poniendo así en un primer plano las cosas que las personas dicen sobre los fenómenos a estudiar. Pero no solo eso, sino que también trajo consigo unos cambios radicales en cuanto a la forma de ver y entender el mundo, nuevas concepciones acerca de la naturaleza del conocimiento, resignificar lo que se puede entender por realidad, tanto social o cultural como natural o física y, consecuencia de esto, diseñar nuevas formas de investigación con un diferente transfondo teorético y otros enfoques metodológicos (Íñiguez, 2006). Entre estas aportaciones se 
encuentra el carácter performativo del lenguaje de John Austin, en el que, desmarcándose de la idea de que el lenguaje es representativo de la realidad, la constituye; decir es también y siempre hacer. El lenguaje no solo instituye el mundo sino que también actúa sobre él (Íñiguez, 2006).

La entrevista individual es una conocida técnica de recogida de información:

Se trata de una conversación entre un/a analista y un/a informador/a para obtener las opiniones, conocimientos, juicios y experiencias mediante la interacción en un contexto de relativa formalidad, aunque incentivando el diálogo fluido y espontáneo. La modalidad de entrevista utilizada en la investigación ha sido la semiestructurada, que consiste en el planteamiento sucesivo, no de preguntas, sino de directrices temáticas derivadas tanto de los objetivos de la investigación como de la evolución propia de la entrevista (Pallarès et al., 2002: 441).

Y en el caso que nos ocupa - continuando con la cita-, de las fotografías. Este tipo de entrevista fue la más pertinente para basar la técnica de la fotoprovocación en nuestra investigación, pues por los objetivos de la misma requeríamos un guión flexible que trascendiera las fotografías y que al mismo tiempo se pudiera integrar con ellas, en la medida de lo posible. Este guión fue confeccionado procurando la menor carga posible de términos teóricos y centrado en la explicación del desarrollo de un día normal de trabajo de las personas entrevistadas. En el transcurso de esa explicación, guiada por la conversación sobre las fotografías, desarrollábamos preguntas pertinentes de su contexto de producción (quién la hizo, dónde es, quién es esa persona, etc), y también sobre aspectos como su relación con la familia, los jefes, el significado de autonomía y la dependencia en el trabajo, la medicación, entre otros.

De esta manera, el intento de unir las fotografías tomadas como un hilo conductor de una narración sobre un día normal, facilitaban enormemente la fluidez de la conversación entre los analistas y los entrevistados, cuya estructura de conversación —en algunos casos y sin ánimo de desautorizarla — distaba de la que podemos usar en un discurso académico, permitiendo un punto común de anclaje. El hecho de que hubiera habido una reunión previa y que las personas asistieran a la entrevista habiendo tomado las fotografías, permitía una facilidad de acercamiento en un primer momento, pues ya intuían de qué se trataba. Al perfilar las primeras preguntas introductorias y tras la petición de la explicación de las fotografías, la fluidez de la entrevista siempre iba in crescendo, al punto de crear rapport rápidamente, y permitir abordar ciertos temas más delicados con mayor fluidez. 


\subsection{Presencia: Observación Participante Puntual}

La observación participante puntual fue la técnica llevada a cabo junto la foto-provocación y que ha servido para darle una mirada adicional desde la presencia apuntando a la pregunta de investigación. Se trata de una breve inmersión de tipo etnográfico en el campo, acompañando a algunos participantes en su jornada laboral, y que incluye la escritura de un diario de investigación.

La observación participante (OP) es característica de la etnografía, en sí la inmersión en el campo. En esencia se trata de la participación del investigador en el contexto estudiado, de manera no encubierta y libre de estructuración, sin matrices ni protocolos de actuación (Íñiguez, 1999: 501).

La ortodoxia antropológica ha intentado mantener la definición propia de etnografía, pero los desarrollos de las demás ciencias sociales en la investigación cualitativa la han ido retomando como un instrumento multidisciplinar y flexible fuera de los límites establecidos. Pero ha resultado ser una ardua tarea (Guasch, 2002; Silva Ríos \& Burgos Dávila, 2011).

Se han puesto en cuestión algunos de los pilares que han definido la etnografía. Óscar Guash (2002), por ejemplo, cuestiona la distancia social - que el contexto de investigación fuera ajeno y lejano al antropólogo- que se exige en la ortodoxia antropológica. Lo que sostiene el autor es que esta distancia responde más al mantenimiento del estatu quo de la disciplina que no a cuestiones epistemológicas relevantes. La duración en el campo fue otro aspecto a debatir, pues las definiciones clásicas de etnografía implicaban largas estancias con la cultura a conocer.

Las alternativas propuestas han considerado el enfoque cuasi-etnográfico (o de Tipo etnográfico), puesto que, sin reunir las características propias de la etnografía, reúne las condiciones para construir un conocimiento pertinente para ciertas preguntas de investigación. "Cuando la etnografía se realiza durante un breve espacio de tiempo y de manera extensiva, los diseños de investigación pasan a denominarse «de tipo etnográfico»" (Íñiguez, 1999: 500).

Carlos Silva y César Burgos hablan del tiempo mínimo-conocimiento suficiente en la cuasi-etnografía sociotécnica (2011), en la línea de diversas investigaciones que tienen como común denominador una corta estancia en la situación a investigar y la explicación exhaustiva del fenómeno social a partir de dicha experiencia. Lo que marca la duración de la estancia y el conocimiento suficiente es la relación entre la información recopilada y la pregunta de investigación. El momento en el que la primera resulta repetitiva y no aporta nada a la segunda es cuando se alcanza aquello conocido como saturación y que debería suponer el fin de la inmersión en el campo.

Justamente es la no-saturación lo que diferencia la observación participante puntual de cualquier otra modalidad de observación participante, etnografía, estudios de tipo etnográfico, etc.

La OPP no debería entenderse como una técnica aislada, pues carecería de valor investigador. La duración puede estar estipulada de antemano como en el caso de esta misma investigación, a sabiendas que no hay que esperar a que los 
datos digan basta. No significa que la saturación no sea importante, pero en este caso la saturación se alcanza en el conjunto de las técnicas, de las cuales la OPP funciona como auxiliar. Algo así como entrar un poco en el campo para tener la oportunidad de dar un contexto mínimo en primera persona a la información recopilada con otras técnicas. La experiencia también puede servir de inspiración para elaborar el guión de entrevista o aspectos a desarrollar adicionales en el transcurso de la investigación.

Así, la observación participante puntual que ponemos en práctica en este estudio tiene un carácter mucho más modesto que la etnografía y la OP. No hay aquí un interés en alcanzar con esta técnica el conocimiento profundo de una sociedad o una subcultura y, aunque incluye escritura de diario de campo, su análisis se mimetiza entre las fotografías y las entrevistas.

\section{UNA APLICACIÓN: AUTONOMÍA Y VIDA LABORAL DE PERSONAS DIAGNOSTICADAS CON TRASTORNO MENTAL SEVERO}

Este dispositivo metodológico fue construido para la realización de una investigación sobre la autonomía y la vida laboral de personas con diagnóstico de Trastorno Mental Severo (TMS).

Las personas que poseen el diagnóstico de algún TMS suelen tener dificultades para iniciar y mantener un trabajo, debido por un lado a la carga de estigma que se manifiesta particularmente en la exclusión laboral, y por el otro lado, a la dificultad que supone compatibilizar su trabajo con las características propias de su situación, ya sea la sintomatología o los diversos efectos secundarios de la medicación.

Los Centres Especials de Treball (CET) son una estrategia para la inclusión laboral de este colectivo, que se basa en el empleo protegido. El objetivo de esta investigación es conocer los ejes de la cotidianidad que potencian la autonomía en la vida laboral de las personas diagnosticadas en un CET. El marco teórico gira alrededor de la comprensión del trabajo en la sociedad y el entendimiento de la autonomía de Richard Sennett.

La seguridad de un trabajo - aunque no exento de algunas dificultades, aún es posible para la gente convencional- es uno de los mayores escollos en la cotidianidad de los diagnosticados, pues suelen tener dificultades para encontrarlo y mantenerlo por las razones antes aludidas.

Desde el cierre de los hospitales psiquiátricos, y conociendo esta problemática, se han elaborado numerosas estrategias diseñadas para que los diagnosticados inicien, mantengan o recuperen su vida laboral con la guía de profesionales en salud mental en la mayoría de los casos. Las principales han sido el empleo con apoyo y el empleo protegido, que en el contexto catalán es encarnado en los Centres Especials de Treball (CET, en el resto de España CEE, Centros Especiales de Empleo).

Así pues, la finalidad de esta investigación fue contribuir a la comprensión

EMPIRIA. Revista de Metodología de Ciencias Sociales. N. ${ }^{o}$ 35, septiembre - diciembre, 2016, pp. 175-204. ISSN: 1139-5737, DOI/empiria.35.2016.17173 
del cotidiano laboral sobre el que, eventualmente, se potencia la autonomía de las personas con diagnóstico de TMS. Siguiendo a Richard Sennett entendemos la autonomía como un proceso relacional que se actualiza constantemente en el trato, siendo un tipo de autonomía que promueve la cohesión social y la ayuda al otro, y en el que la dependencia es una relación de reconocimiento mutuo, $\mathrm{y}$ es posible que sea manejada de una manera respetuosa y no denigrante, por ejemplo, mediante el reconocimiento de autonomía (Sennett, 2003). Esta manera de entender la autonomía se contrapone a la manejada en occidente actualmente, promovida por valores como la búsqueda del éxito laboral en un contexto de mercado laboral flexible, que mina las relaciones sociales en su base y, cómo no, corroe el carácter (Sennett, 2005), además que entiende la dependencia como una condición vergonzosa, cercana a la niñez y totalmente indeseable.

Esta investigación ha sido llevada a cabo con trabajadores del CET ARAPDIS en el barrio de Gracia de Barcelona, a quienes agradecemos su disposición. Esta elección responde al tipo de organización y al perfil concreto de participantes: aquéllos diagnosticados con algún TMS que estén compensados (es decir, con pocas posibilidades de tener delirios o alucinaciones, y en general con toda la sintomatología controlada por medio de la medicación). El empleo protegido, en este contexto, es un trabajo con salario, dirigido a personas diagnosticadas con TMS (o alguna otra dificultad) y que cuenta con la asistencia de profesionales de la salud mental (García-Villamisar, Wehman, \& Navarro, 2002).

\subsection{Diseño}

Para el proceso de la investigación ha sido útil tener en cuenta cuestiones propias de las técnicas a utilizar. El tipo de entrevista planteada es en sí una práctica social vinculada con la tecnología, que le da un carácter específico. La visualización y significación de las imágenes está enmarcada en dicha práctica social, por ejemplo: sería muy diferente ver las mismas fotos en una galería o enseñárselas a un familiar. Las características de los objetos y la situación de entrevista tienen características con consecuencias más o menos sutiles, y fue necesario tener en cuenta los factores más relevantes para diferentes fases de la investigación como el diseño, el trabajo de campo y el análisis. Esto tiene que ver con decisiones como escoger el tipo de cámara (digital o analógica) o la manera de visualizar las fotos (digital o impreso).

Las primeras decisiones fueron relativas a la producción. En la literatura hay muchas variaciones con respecto al diseño de las investigaciones que usan fotografías. Así, podemos encontrar el uso de cámaras desechables (Castleden, Garvin, \& First Nation, 2008; Lopez, Eng, Randall-David, \& Robinson, 2005; Thompson et al., 2008) o digitales (Johnson, 2012; Labbo, Eakle, \& Montero, 2002). En el caso del uso de cámaras desechables el límite de fotos es técnico, pueden ser 12, 24 o 27 fotos; en el caso de las cámaras digitales se suele pedir un límite de fotos, ya que la limitación técnica supondría cientos o miles de

EMPIRIA. Revista de Metodología de Ciencias Sociales. N. ${ }^{\circ}$ 35, septiembre - diciembre, 2016, pp. 175-204. ISSN: 1139-5737, DOI/empiria.35.2016.17173 
fotos. En cualquier caso, suele haber una selección posterior de fotos a trabajar en la entrevista, en Thompson et al. (2008) el investigador principal consideró que la selección de cuatro fotos (de entre 10 y 27) era suficiente para saturar la entrevista; Johnson (2012) limitó a 15 las fotografías para tomar y para la entrevista, y luego cada participante seleccionaba 3 para una exposición al respecto. Asimismo, existe variación entre el tipo de entrevista: individual (Hodgetts, Radley, Chamberlain, \& Hodgetts, 2007; Radley \& Taylor, 2003) o grupal (Epstein et al., 2006; Johnson, 2009).

En el trabajo de campo trabajamos con ocho personas del CET (Centre Especial de Treball) ARAPDIS, quienes rellenaron un consentimiento (o en su defecto sus tutores) de la participación en la investigación. El mismo perfil de admisión al empleo protegido da cuenta del perfil de los entrevistados. Son personas con diagnóstico de TMS, compensadas, es decir, con la sintomatología controlada, como los delirios o las alucinaciones. La selección de personas ha sido hecha por el CET según la disponibilidad y disposición de los trabajadores, en todos los casos de manera voluntaria.

La toma de datos fue llevada a cabo entre noviembre de 2011 y marzo de 2012 en dos fases. La primera de ellas consistió en dos reuniones grupales con las instrucciones de la toma de fotos (la primera al inicio del proceso con un primer grupo de trabajadores, y la segunda en la mitad, con el segundo grupo), y la entrega de una cámara digital compacta que ha rotado entre ellos con la ayuda de coordinadores del centro. El límite de fotos fue poco relevante, con la ventaja de que permite seleccionar y borrar fácilmente las fotos, $\mathrm{y}$ utilizar un temporizador, característica que no está presente en las cámaras desechables. Las instrucciones fueron que, en un día normal (día laboral), tomasen fotos que representasen diferentes aspectos de su vida: con los que se sintieran confortables y con los que creyeran que podrían mejorar; aspectos en los que sintieran autonomía o dependencia. Deliberadamente se apostó por la ambigüedad de las instrucciones para que fuera su propio criterio el que guiara el foco de atención. Esta apuesta tuvo resultados variopintos, desde la monotonía exclusiva de ciertas tareas laborales hasta un repaso de las caras vistas a lo largo del día.

La segunda fase fue la entrevista de foto-provocación; corresponde a entrevistas individuales con base en las fotos tomadas, utilizándolas como guía de una narración de un día cotidiano, que a su vez conectan con la mayoría de los aspectos a tratar en el guión de entrevista textual, aprovechando para su profundización. Los puntos que no surgen espontáneamente en la conversación fueron tratados al final de la entrevista uno a uno, según fluía la conversación, tomando forma de entrevista semiestructurada clásica. Valga aclarar que en esta propuesta metodológica la foto-provocación hace parte de todo el proceso, desde el primer acercamiento y la entrega de la cámara, momento en el cual se empieza a perfilar la planeación de las mismas fotografías que fue efectuada días o semanas más adelante y la misma entrevista.

El lugar de las entrevistas fueron diversas oficinas de la institución, cambiantes según la disponibilidad. Las limitaciones propias del trabajo de 
campo no permitieron realizar las entrevistas en lugares ajenos a la institución, que hubieran permitido marcar una distancia para hablar de ella misma, situación ideal. A cambio de no conseguir dicha distancia simbólica, tuvimos la facilidad de contar con alguna oficina para cada una de las entrevistas, de fácil acceso para los participantes, suficientemente privada y aislada acústicamente, cosa que habría sido muy difícil de conseguir sin su apoyo.

La tercera fase fue la observación participante puntual con tres de los participantes - uno de ellos en dos sesiones - a lo largo de media jornada laboral. Dos de ellos en ese momento realizaban tareas en la copistería y transportaban correspondencia y el tercero trabajaba en la lavandería del centro.

Concretamente, de los ocho participantes, todos realizaron las fotografías de su día laboral, y la entrevista fue hecha a siete de ellos. Hubo tres observaciones participantes puntuales, de las cuales una fue el mismo día de la toma de fotografías; los otros dos participantes tomaron las fotografías un día diferente.

\subsection{Procedimiento de análisis}

Dada la naturaleza del material obtenido en el proceso metodológico de la investigación y de su conceptualización teórica, el proceso de análisis no puede perder el camino marcado. En primer lugar, explicaremos algunas características de las fotografías utilizadas y cómo condicionan el proceso de análisis y su relación con lo trabajado hasta este punto, teniendo en cuenta el centro de gravedad metodológico: las imágenes.

\subsubsection{Imágenes}

Fiske (1994, citado por Rose, 2001) señala que las imágenes tienen sus significados renegociados (incluso rechazados) por varios aspectos contextuales, lo que él llama audiencing, que podría ser, en efecto, la misma audiencia a la que se dirige la imagen en un momento dado o las circunstancias específicas. Rose lo descompone en tres partes; la primera es la composicionalidad: hacia dónde lleva la mirada el orden de los elementos. En el caso de las fotografías no profesionales usadas en esta investigación lo más importante a tener en cuenta es qué ocupa el centro. La accidentalidad periférica también es tenida en cuenta y a menudo es una buena excusa para hablar sobre otras cosas, como los compañeros que aparecen o la distribución del espacio de trabajo o de ocio.

La segunda parte que señala Rose es la tecnológica, refiriéndose a la tecnología de exhibición. Por ejemplo, existen diferencias obvias entre ver una película en la televisión de casa y ver la misma en el cine con gafas 3D, por ejemplo, pero esas diferencias no sólo pasan por lo técnico: tamaño, colores, relieve simulada, calidad del sonido... sino también en la misma experiencia vivida, también relativa a la disposición que se tiene por el contexto de exhibición (Rose, 2001). Por ejemplo, para mucha gente la disposición podría 
ser diferente al pagar los elevados precios del cine comercial o no pagarlos, estando en casa.

Y por último y más importante, la tercera es la social, íntimamente relacionada con la anterior. El contexto de exhibición marca fuertemente la manera como interpretamos la imagen. Ciertos tipos de imágenes suelen estar asociados a ciertos contextos: la televisión en la sala de casa y los lienzos en el museo inspiran una contemplación muy diferente. No se trata sólo de la tecnología utilizada; cada uno fue hecho de manera diferente para espacios diferentes. Así, no solemos comprar crispetas para entrar a los museos, ni las cenas caseras se hacen en solemnes contemplaciones casi reverenciales a una obra (Rose, 2001).

Muchos de los análisis visuales tienen en cuenta todos los aspectos de la fotografía, y pueden hacerlo porque normalmente se centran en la fotografía profesional. En éstas, todas las características están cuidadas más o menos milimétricamente, dependiendo si es en estudio o en otras situaciones. La composición - lo que entra en el encuadre y su posición- el enfoque, el tiempo de exhibición, el nivel de zoom, la viveza de los colores, por no mencionar los múltiples retoques y montajes que se pueden hacer digitalmente...- todo responde a decisiones meditadas, motivos más o menos conscientes susceptibles de ser analizados en profundidad.

En el caso de la fotografía amateur — que es lo más próximo al resultado de este tipo de experiencias - todos estos aspectos son mucho menos susceptibles de análisis —al menos para nuestros objetivos_- pues sería pretencioso buscar significados profundos en acontecimientos aleatorios $-\mathrm{O}$ al menos aleatorios en relación con la subjetividad de los participantes- En el caso de esta investigación, menos uno, todos los participantes utilizaron la misma cámara digital compacta de gama baja con todos los ajustes automáticos, por lo que los aspectos relativos a la viveza de los colores, el uso o no de flash, tiempo de obertura del obturador, etc., sólo podrían ser analizados a nivel técnico mediante la ingeniería inversa de la cámara utilizada, pero no a nivel psicosocial. En términos de composición, las personas con menos práctica a nivel de fotografía profesional normalmente se ocupan de lo que se quiere enseñar en el centro y a veces en el fondo, a manera genérica como parte de un paisaje, sin que suponga mayor preocupación por la composición en la mayoría de los casos. Es por esto que el mejor análisis de las fotografías no profesionales es el que está ligado a las palabras de sus creadores.

\subsubsection{Análisis Temático de Contenido}

El proceso de análisis se centró en identificar los principales ejes de la cotidianidad laboral de los participantes y qué dicen y enseñan de ellos, y cómo los ejes se relacionan entre sí. Dado que no se trata de un diagnóstico de autonomía individual, sino de la experiencia de la cotidianidad laboral, por lo que el material fue analizado de manera mezclada, es decir, las fotos fueron 
agrupadas con segmentos de entrevistas que no necesariamente corresponden con sus autores.

El proceso llevado a cabo fue basado en el Análisis Temático de Contenido (ATC), que, definido de la manera más genérica, es un proceso interpretativo que se trata de dividir cantidades importantes de texto en unidades o citas que se agrupan en categorías por el criterio de analogía — similitudes o semejanzas entre ellas-, y estas categorías pueden surgir del texto o venir dadas de antemano, desde la conceptualización teórica y la pregunta de investigación, por ejemplo (Vázquez, 1996). La primera estrategia es conocida como bottom-up, y la segunda como up-buttom (Muñoz Justicia, 2004: 34). En las investigaciones con entrevistas la más usada es la de bottom-up, pues permite que las categorías emerjan de la voz de los entrevistados, aunque no hay que perder de vista que estas palabras fueron dichas en respuesta a un guión de entrevista semiestructurada, por lo que hay que entender las categorías resultantes como un producto de procedencia híbrida entre la pregunta de investigación, la interpretación del investigador y la teoría que inspiró el guión de entrevista, con especial énfasis en las palabras de los entrevistados. El proceso es circular, a partir de la lectura y relectura (y escucha) de las transcripciones, se van creando las categorías y se refinan hasta saturarlas.

La familiaridad con el material viene desde la misma realización de la entrevista (la voz del investigador hace parte del mismo material), también en el proceso de transcripción en el que, por lo general, la mayoría de las frases son escuchadas varias veces. Una sucesiva lectura-escucha viene en el momento en el que se sincroniza el audio con el texto. Otra lectura, cuando se intercalan las imágenes con las palabras-audio. Y otras cuantas lecturas cuando se vuelve a leer y releer para categorizarlo.

El análisis lo realizamos con la ayuda del programa informático Atlas.TI 6.0, que permite añadir el texto y sincronizarlo con el audio de las entrevistas y seleccionar fragmentos que forman o se integran a las categorías. Estas categorías permiten múltiples operaciones analíticas al permitir agrupaciones de las mismas y conceptualizarlas en redes visuales que hacen las veces de mapa conceptual.

Una vez realizado el mapa conceptual de categorías, el siguiente paso del proceso fue una recategorización up-bottom: utilizar las categorías para codificar las imágenes, los fragmentos de diario de campo y la teoría que le pueda corresponder. Así, la primera categorización con énfasis en la palabra de los participantes guía la categorización del resto de material, incluído el teórico. En el resultado final, dentro de cada categoría no hay distinción entre participantes, fuente o formato del material, dando riqueza conceptual a cada una de las categorías e ilustrando de diferentes maneras los ejes de cotidianidad, y de esta misma manera es como se presentan los resultados: categorías con fuentes híbridas que dan cuenta de la experiencia laboral de un aspecto concreto, con fotos y palabras de diferentes personas, con sus disputas y contradicciones, como todo discurso.

El resultado del primer proceso dio lugar a 71 códigos agrupados en 16 
familias y éstas, a su vez, en 9 superfamilias, sobre estos resultados.

Este producto fue sedimentado en el siguiente estadio del análisis, en el que se fusionaron y eliminaron la mayoría de categorías siguiendo la línea marcada por las líneas teóricas analíticas y la pertinencia del hilo narrativo, dando lugar a 18 códigos, agrupados en 5 familias, y éstas a su vez, en 2 superfamilias, como se explicará más adelante.

El análisis temático de contenido (ATC) es el método analítico más acorde a las características de la pregunta de investigación y al material recopilado, ya que permite profundizar en las prácticas que describe. No se trata de extraer una realidad exterior de las palabras y las imágenes, sino de co-construirla a partir de éstas y dar cuenta de los ejes de la cotidianidad laboral, de la que sobra decir que es una experiencia subjetiva. Además, comparando el ATC con sus métodos analíticos limítrofes (Análisis lingüístico, de discurso), el ATC es el único que facilita la inclusión de las imágenes, y no se centra en las interacciones discursivas, la estructura del lenguaje o las relaciones de poder en el discurso.

Esta misma flexibilidad del ATC permite un análisis de deductivo o inductivo según la conveniencia, y para esta investigación es inductivo y deductivo. El primer proceso inductivo procede a generar las categorías de los datos y asegura máxima conexión del análisis con las entrevistas (Alhojailan, 2012), además, tal como señalan Huberman y Miles (2002), es una estrategia útil cuando el terreno es poco familiar, complejo — como es el caso del análisis del híbrido de imágenes y palabras-, o con pocos casos. El diseño deductivo, como señalan estos mismos autores, es útil cuando se tiene familiaridad con el terreno investigado y los conceptos están bien delineados. En el caso de esta investigación nos fue útil ambas aproximaciones, dotando de mayor agencia a las palabras de los entrevistados.

La segunda fase deductiva permite que el resto de datos reconecten con las categorías de manera guiada por las palabras de los participantes, es decir: las categorías ahora hacen las veces de la teoría que se contrasta con las fotografías, con el diario de campo, teoría, resultados de otras investigaciones, etc. Sobre estos dos últimos materiales mencionados — materiales que en un estadio anterior inspiraron el guión de entrevista y parte del marco de la investigación-, valga decir que se utilizaron a la par de los otros materiales en la segunda fase deductiva. Este pequeño giro a la manera tradicional de realizar el ATC (que suele tener una inclinación más marcada hacia procesos inductivos o deductivos) permite que en el análisis las palabras de las entrevistas tengan más agencia y que surjan categorías no previstas. Si bien es cierto que la mayoría de categorías no supusieron ninguna sorpresa-dado que la entrevista tenía un guión confeccionado en parte por ese mismo material_- esta manera de asignar la teoría y resultados similares u opuestos de investigaciones previas, facilitó enormemente el paso a otras categorías que, de otra manera, quizás no hubieran surgido, o lo hubieran hecho de una manera diferente. Un ejemplo: en el guión de entrevista evitamos utilizar términos técnicos como "rehabilitación psicosocial", pero, inevitablemente, salió por parte de los entrevistados, surgiendo como categoría. En el análisis de esta, vinculado a la presentación 
de sus resultados (fotografías, palabras y diario de campo), fue útil explicar su conceptualización teórica que fue anclada a esta categoría en esta segunda fase, junto a una fotografía que fue manifiestamente vinculada a este concepto (se trataba de un local llamado "arte-sana") y esta comparación y puesta en relación fue parte de su análisis. Así, cada categoría recibía un análisis interno de relación entre sus elementos con sus similitudes y contradicciones, y también de la puesta en relación con otras categorías.

\section{ALGUNOS RESULTADOS REPRESENTATIVOS}

En este apartado presentamos algunos resultados relevantes de la investigación llevada a cabo, a manera de ejemplo del uso de la metodología. Se podrá revisar una presentación más extendida en futuras publicaciones derivadas de la investigación centradas en los resultados. Tras la sedimentación de la gran cantidad de categorías resultantes del primer proceso de categorización, los resultados finales fueron agrupados en dos grandes grupos: el primero relacionado con la vivencia de la enfermedad mental y la relación con las instituciones, llamado términos e instituciones PSI; y el segundo llamado Rutina y trabajo, que explicaremos más adelante (ver figura 1).
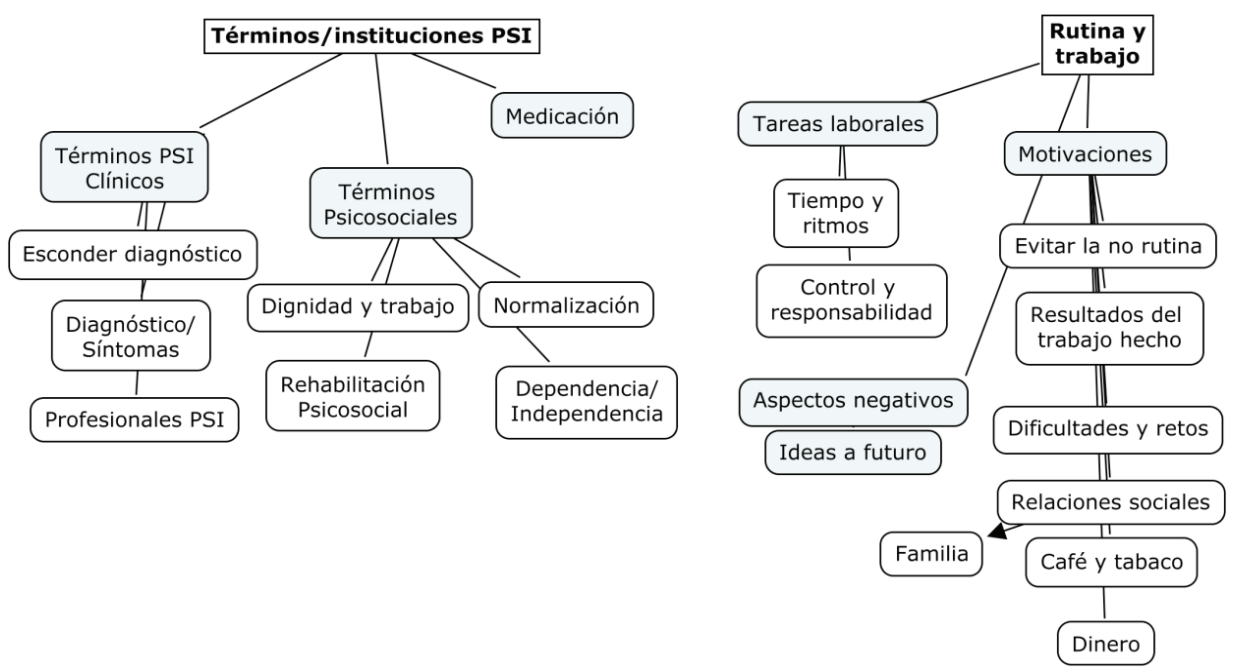

Figura 1. Categorías de análisis 


\subsection{Términos e instituciones PSI}

El primer grupo de resultados agrupados en la sección izquierda de la figura 1 es la parte más discursiva y disciplinar del análisis. A lo largo del trabajo de campo se mantuvo cierta ambigüedad evitando el uso de tecnicismos y sin ceñirnos a sus definiciones. Inevitablemente fueron surgiendo términos procedentes de las disciplinas PSI (psiquiatría, psicología clínica y psicología social), pues estos impregnan el discurso occidental, especialmente en las personas que por diversos motivos están circundando este tipo de instituciones. El análisis de estos usos da cuenta de la inteligibilidad que le dan las personas diagnosticadas a su situación, y de la manera como construyen el mundo, teniendo en cuenta que el lenguaje es constitutivo de la realidad.

Este grupo se divide en dos partes: la primera centrada en los aspectos clínicos y psiquiátricos, y se trata de la relación más directa entre las personas diagnosticadas y diferentes aspectos como la medicación, los profesionales PSI (Psicólogos, psiquiatras y otros trabajadores del CET) y la manera de gestionar los síntomas y la misma etiqueta diagnóstica en el ámbito laboral y la sociedad.

Para lo que nos ocupa en este artículo presentaremos sólo unos ejemplos de imágenes y palabras de algunas de las categorías insertas en las agrupaciones presentadas en la figura 1, y por las limitaciones propias de este formato, dejaremos a un lado el análisis minucioso de cada una, dejándolas insertas en la presentación general de resultados a manera de ejemplo de resultados de fotoprovocación.

Sobre el uso de la medicación psiquiátrica, algunos entrevistados destacaban la importancia de la responsabilidad que les era cedida en su propia administración, que era entendida como un aspecto importante de la autonomía (o independencia, pues en su discurso se utilizaban ambos términos indistintamente).

Bueno, pues, a veces el doctor me manda a buscar medicación psiquiátrica y entonces me elige a mí porque conozco la, la clínica desde que empezó, y conozco la enfermera. Y bueno, me hace sentir independiente que, aunque son medicación psiquiátrica, o que son cosas un poco mentales, pues yo tengo pues autonomía para ir a buscarlas, y aunque, por ejemplo, que [A.] se lo tome, o yo (Rafael, entrevista personal, 21 de diciembre de 2011, ver figura 2) ${ }^{2}$.

2 Usamos seudónimos para guardar la identidad de los participantes. 


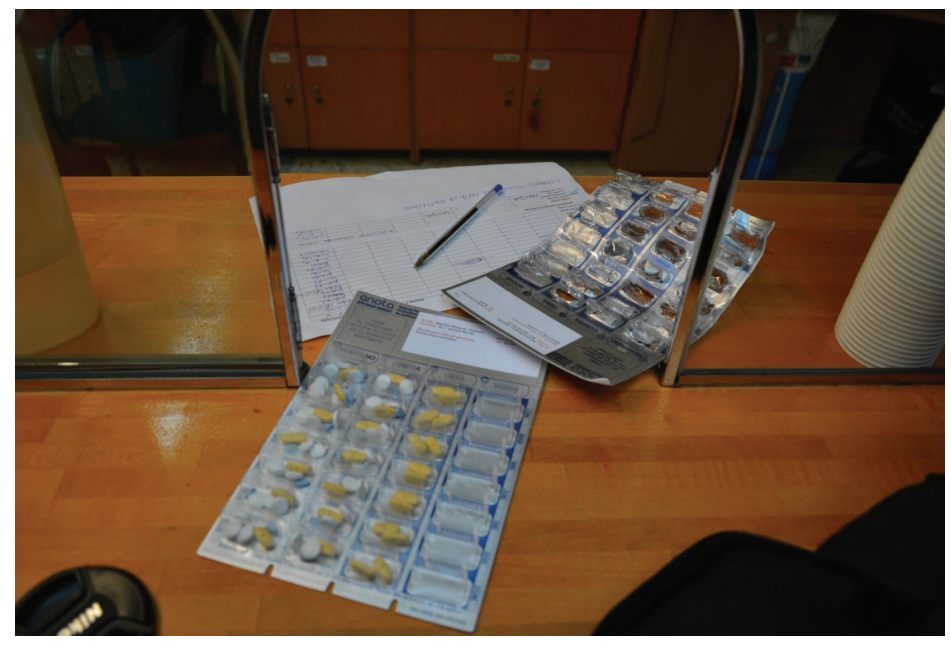

Figura 2. Fotografía 22 de Adrián

La propia medicación era vista también como "una de las patas de la rehabilitación, la otra es la familiar, la otra es la social". (Adrián, entrevista personal, 9 de enero de 2012).

Deegan y Drake (2006) realizan un estudio sobre la toma de decisiones compartida en la administración de la medicación, centrado en la efectividad del consumo. Encuentran que la actitud pasiva y sumisa de tomar las pastillas resulta contraproducente, siendo un modelo heredado del paternalismo médico. Dicho modelo falla en captar la complejidad de las dinámicas de los clientes autónomos, quienes tienen que manejar conflictos de decisiones durante años o décadas. Explican que el modelo de toma de decisiones compartidas permite evaluar las ventajas y desventajas del proceso, respetando la autonomía del paciente y su propia experticia. Aunque en los extractos presentados no se hablaba de decisiones sobre la misma medicina sino sobre su responsabilidad en la administración, unos resultados y otros van en la misma línea.

La segunda agrupación se refiere a los términos de ciencias sociales. Se trata de diferentes usos lingüísticos sumamente dispersos — de ahí ese título tan genérico-pero todos relacionados con la experiencia cotidiana del diagnóstico y la inteligibilidad del proceso. En este apartado exploramos la relación entre dignidad y trabajo, la idea de normalización, la apropiación del concepto de rehabilitación laboral y de dependencia e independencia, bastante ligados con la autonomía.

El ejemplo a exponer de esta agrupación es sobre una de las acepciones de "independencia", que, en sus palabras, estaba directamente ligada a la realización efectiva de sus tareas. Oscar señalaba: 
Entrevistador: ¿Hay alguna foto que simbolice de alguna manera tu independencia?

Óscar: En el sillón éste, pues lijar, saber que lo has lijado y que, que, que, luego tienes que teñirlo o barnizarlo tú solo, pues sí que siento independencia, sobre todo con, de las tareas que hacemos con los muebles, con la que más [...] más gratificantes, y cuando, cuando acabas, también cuando pones el barniz bien puesto, o lo enceras un mueble ya, cuando está barnizado, le pones cera y lo acabas de pulir, limpiar, pues también, también (Óscar, entrevista personal, 11 de abril de 2012, ver figura 3).

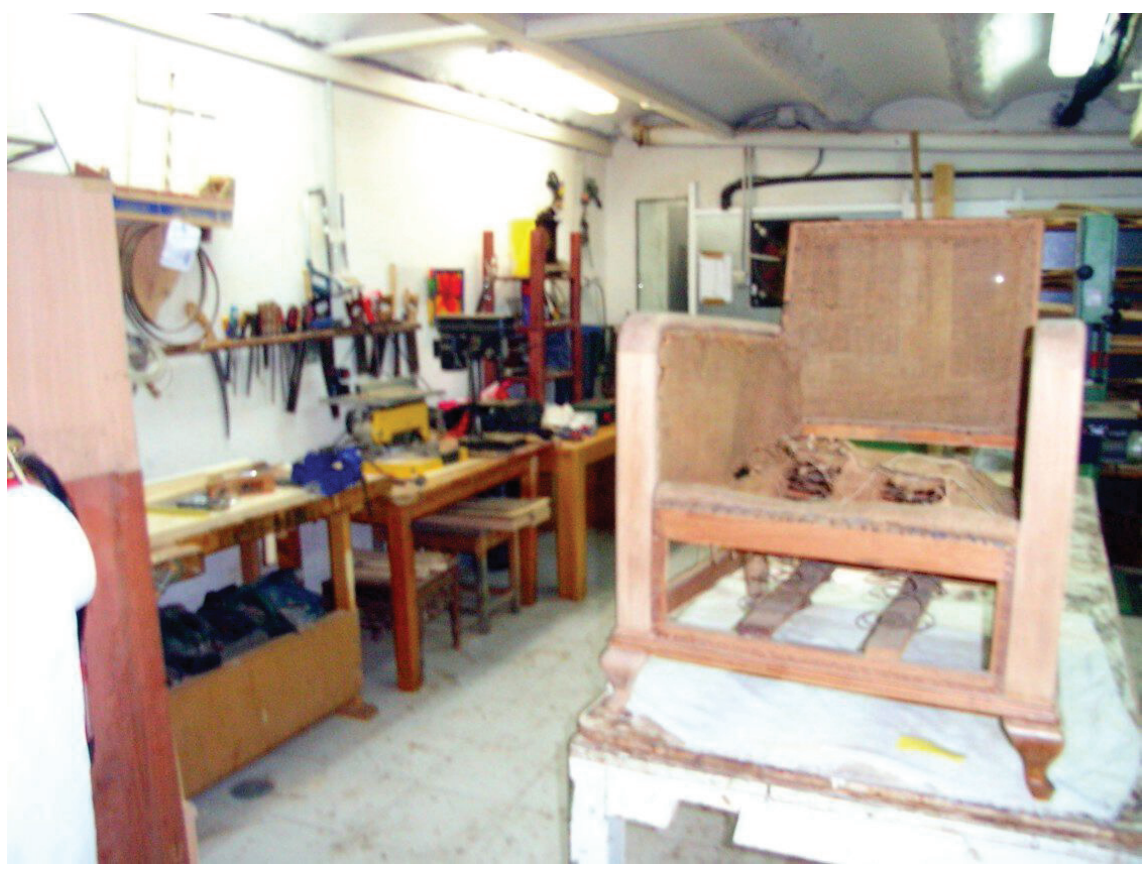

Figura 3. Fotografía 2 de Óscar

La independencia, utilizada como sinónimo de autonomía y antónimo de dependencia en el discurso dominante y en el suyo propio. Este entendimiento de la autonomía como ausencia de dependencia se desarrolla en la ilustración $\mathrm{y}$ es heredado por el pensamiento neoliberal imperante que ha permeado completamente el discurso común. Así, de la dependencia se desprende cierta vergüenza que funciona como una excelente herramienta disciplinaria, pues el ciudadano interioriza la idea de que aquél que depende está consumiendo recursos y no produciéndolos, y procurará así la maximización de su propia productividad (Sennett, 2005, p. 147). Es por esto que no es de extrañar que la independencia aparezca ligada a la realización efectiva de tareas individuales, como sucede en el ejemplo señalado y algún otro en las demás entrevistas. 


\subsection{Rutina y trabajo}

El siguiente gran bloque es sobre rutina y trabajo, que es la parte central del análisis y que ocuparon el grueso de las entrevistas. Se divide en dos bloques mayores y dos menores.

De los bloques mayores, tenemos las tareas laborales, una exploración del aspecto más directamente tangible de la cotidianidad laboral, indagado desde la óptica de la rutina explicada por Richard Sennett y las condiciones que debe tener para que no resulte denigrante: por un lado, la posibilidad de tener control sobre los procesos del trabajo y también sobre los ritmos y tiempos (Sennett, 2009). Explorando el material de las entrevistas, encontramos que en gran medida se cumple de manera similar a otros trabajos del mundo competitivo (no protegido), en efecto, tienen margen de decisión para llevar a cabo sus tareas.

En el caso de Iván, que llevaba tareas de limpieza, nos mostraba cómo se organizaban para la limpieza de los lavabos ${ }^{3}$ :

Iván: Cada uno, a lo mejor igual, a lo mejor yo hago los váteres, a lo mejor los he hecho yo, y mañana hago otra cosa ¿sabes? lo vamos combinando.

Entrevistador: $Y$ ¿eso quién lo decide?

Iván: No, esto cada día nosotros lo sabemos, como ya llevamos aquí tiempo, pues ya sabemos cómo va la faena [...] si uno dice, 'oye mira, que hoy [1] lo del váter' Y yo 'vale, pues lo hago yo' entonces el día siguiente me dice 'oye, que yo hoy el váter' Entonces uno limpia los despachos, y la tercera, pues hace otra cosa y el otro hace el váter (Iván, entrevista personal, 10 de abril de 2012, ver Figura 4).

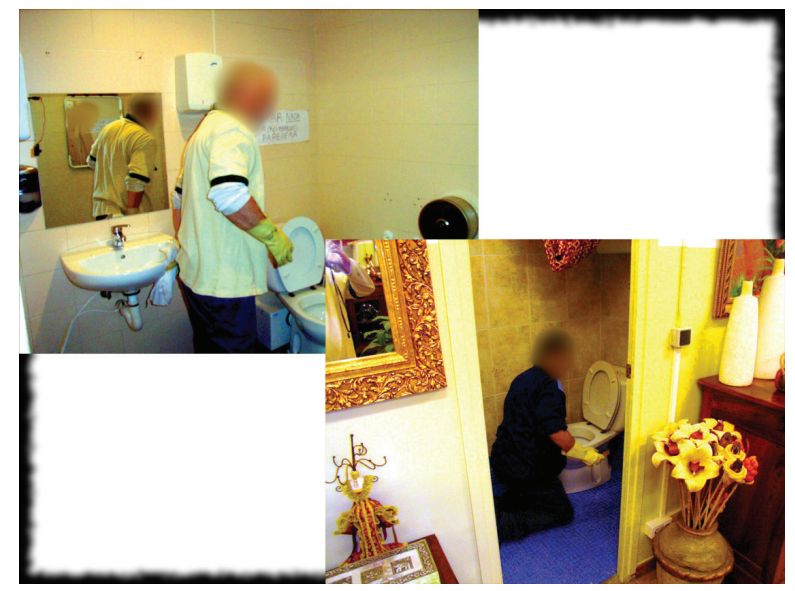

Figura 4. Collage limpieza. Fotografías 9 y 11 de Iván

3 Las caras en las fotos fueron difuminadas para proteger la identidad de los participantes.

EMPIRIA. Revista de Metodología de Ciencias Sociales. N. ${ }^{\circ}$ 35, septiembre - diciembre, 2016, pp. 175-204. ISSN: 1139-5737, DOI/empiria.35.2016.17173 
Una última condición, no menos importante, que es ubicar el foco de motivación del trabajo, y es que la situación ideal es que debería estar en el trabajo mismo, como en el juego (Sennett, 2009). En este caso, y nuevamente de manera similar al mercado competitivo, esta condición se da en una medida mínima. Sin embargo, y esto nos lleva al siguiente grupo, a lo largo del material encontramos diferentes motivaciones que orbitan la rutina, y que hacen que esta valga la pena, relacionadas tanto con la relación entre la rutina y aspectos relativos al diagnóstico, como con las tareas laborales y las relaciones sociales más cercanas e infinitesimales.

Este bloque quisiéramos ilustrarlo con una de las categorías reveladoras, que surgió, en la mayoría de los casos, tras la respuesta a una pregunta: “¿Cuál es tu momento favorito del día?". Se trataba de momento del café: la oportunidad de compartir un cigarrillo o un café con los compañeros en los momentos de desconexión. David respondía de esta manera:

Hombre, el descanso, el descanso. [...] Claro, te estás relajando, sí, sí. Hablamos, con los otros, ver tele, las revistas, no sé [...]. Lo otro, claro, es más mecánico, estás escribiendo, corrigiendo, lo que es más mecánico, más rígido, en el descanso te relajas. Eso creo que le pasará a casi todo el mundo, aunque no lo digan, que dices "es lógico” ¿no? (David, entrevista personal, 28 de diciembre de 2011, ver Figura 5).

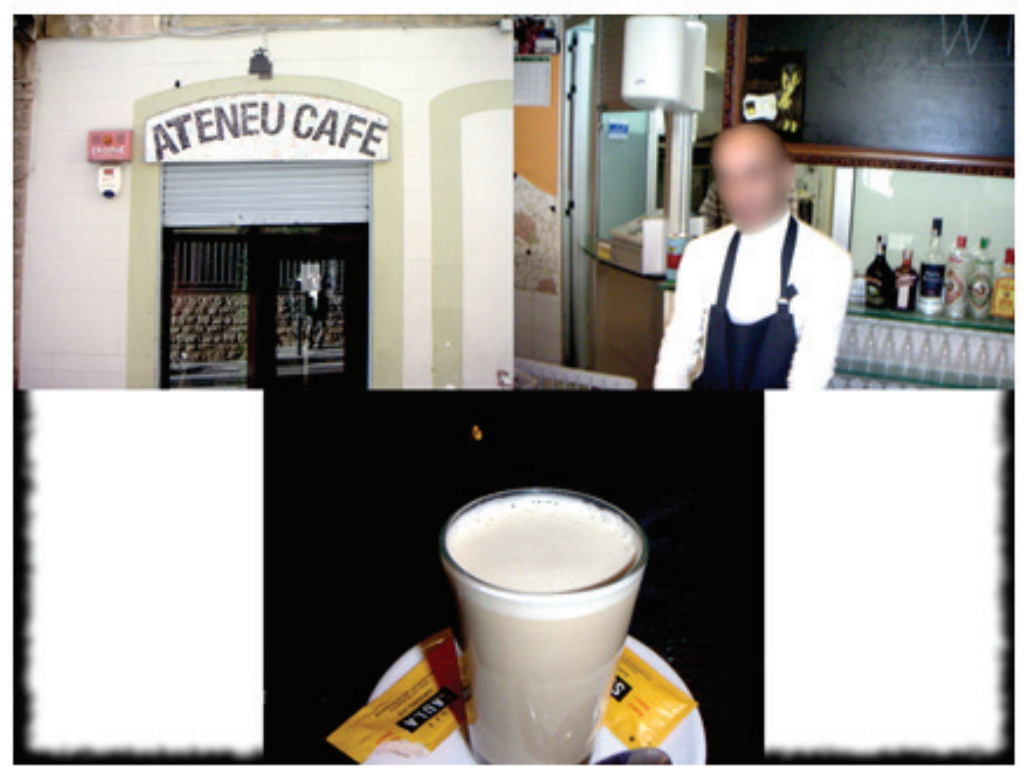

Figura 5. Collage del café. Fotografías 19, 20 y 21 de Rafael. 
El momento del café representa la faceta de socialización que representa la vida laboral y que hacen parte de las motivaciones para asistir al trabajo y tener una rutina laboral, que hace que ésta valga la pena. Este espacio de socialización, además, da pie al fortalecimiento de la amistad o la elaboración de comunidades de enfrentamiento (coping) (Stroebaek, 2013). Fineman y Sturdy (2001, citados en Stroebaek, 2013) señalan la importancia de entender el funcionamiento de las pausas de café, ya que hace parte de la constitución de significados y emociones que se mueven en una organización. En el momento en el que los trabajadores se encuentran informalmente alrededor de una taza de café, se desarrollan conversaciones que incluyen las transcripciones encubiertas de lo que se teje alrededor de la rutina, lejos de los oídos de los jefes o clientes. También es un espacio para hablar de la propia vida, o de otros temas de interés común (Stroebaek, 2013), que funcionan como una clave para lubricar y fortalecer las relaciones. Además, es el escenario ideal para que los nuevos trabajadores se integren efectivamente en el entorno.

\section{Conclusiones y discusión}

El camino para llegar a estos resultados fue marcado por la fotoprovocación: el híbrido entre fotografías y palabras cuyo funcionamiento y efervescencia fue presentado en los dos anteriores apartados.

Tras la conceptualización de la foto-provocación, en su ejecución hemos encontrado, por un lado, que la fotografía permite un punto de anclaje común entre el discurso de los protagonistas esta investigación y el académico. Sin ánimo de desautorizar o menospreciar un discurso con una estructura diferente a la que utilizamos en el medio académico, buscamos presentar en este medio los mismos resultados.

Por otro, la fotografía no va a enseñar una realidad única sobre alguna cosa. Como hemos dejado ver en el segundo apartado La construcción del dispositivo metodológico: Imágenes, palabras y presencia, lo que interesa de la fotografía y de la investigación en general no es la realidad sobre la autonomía, sino la mirada de los trabajadores diagnosticados, que será complementada por la entrevista posterior y la observación participante puntual.

La fotografía, como hemos visto, funciona como un mediador en el sentido latouriano, no representan una realidad que se transmita del pasado al presente ni de una cabeza a otra, y en el contexto de la foto-provocación, la fotografía interviene directamente en la relación, despierta interrogantes, interés... y hasta punctum; anima a entrevistador y participantes, y es animada, estimulando y provocando una colaboración especial en función de la interpretación de las fotografías, formando una construcción que es la narración de la cotidianidad, en nuestro caso, relacionada con el trabajo.

Si comparáramos la situación social que es la entrevista con el funcionamiento de un coche, la fotografía vendría haciendo las veces de gasolina, lubricante y starter (motor de arranque) - pues permite romper el 
hielo al inicio de la conversación- además de ser engranajes en sí mismas. Las entrevistas iniciaban con la conversación alrededor de las fotografías, y en esa conversación explotábamos los diferentes puntos del guión de entrevista. Aquellos aspectos no abordados se desarrollaban después de hablar de las fotografías. Ahora bien, el hecho de haber pasado primero por las fotografías, permite que el motor ya esté en perfecta marcha y funcionamiento, permitiendo abordar temas más delicados con mayor fluidez.

De esta manera, la configuración específica que proponemos, en síntesis, permite presentar una mirada personal de la cotidianidad laboral, que más adelante permitirá fomentar una colaboración en la interpretación, a la vez que hace la entrevista más dinámica y fluida. El tipo de análisis temático de contenido permite una flexibilidad propia para poder moverse entre la lógica inductiva y deductiva, señalando el camino desde las palabras de la entrevista hacia el resto de materiales, y es que también es necesaria esta flexibilidad para poder manejar diferentes tipos de formato de información. Difícilmente el uso de alguna de estas técnicas aisladas o cualquier otra técnica nos permitiría obtener esta riqueza de datos y analítica. En este contexto, el mejor análisis de las fotografías es el que está ligado a las palabras de sus creadores.

En cuanto la ejecución de la OPP, encontramos varias particularidades. Al realizar la OPP antes de la entrevista temíamos que la conversación en la primera quemara de alguna manera los temas interesantes en el momento de la segunda, pero lo que aprendimos fue que, si se presentan estos temas con un resumen y una pregunta de profundización, se puede retomar de manera funcional. Además, las observaciones y las conversaciones durante la OPP pueden ayudar a mejorar el guión de entrevista, ya sea para la misma persona o el guión de entrevista general para todos.

La OPP se incrusta como un intento de formar parte del diálogo creativo que proponen Cowden y Singh (2007) en su discusión sobre la voz de los usuarios en los servicios sociales. Sostienen que, si bien es importante el ímpetu de centrarse en la voz de los usuarios, este centramiento corre el riesgo de mercantilizarse, convirtiendo a los usuarios en una suerte de usuarios profesionales, y la escucha, administrativa. La alternativa, pues, es mantener un diálogo creativo entre investigadores y usuarios, con ánimo emancipatorio. Si bien la voz de los protagonistas y su amplificación está en el foco de esta investigación, no es la única voz: no se trata de elaborar ingenuamente una teoría de ellos, como si la tinta esparcida hiciera las veces de un puente inmaculado, un intermediario laturiano. La incursión en el campo hace parte de la misma apuesta ético-política: buscar un enfoque que permita una mirada adicional en primera persona, complementaria y enriquecedora.

El desarrollo de la foto-provocación estuvo marcado por la ambigüedad de las instrucciones para la toma de las fotografías y también en la formulación de algunas de las preguntas. Algunos de los efectos de esta ambigüedad fue que muchas de las fotografías se centraban demasiado en las tareas laborales en sí, por lo que en algunas entrevistas la parte de fotografías fue rápida, no provocaban - aunque gracias a estas el resto de la conversación fue más 
fluida-; y en el momento de la entrevista a veces no funcionaba tampoco esta ambigüedad, teniendo que concretar a varios niveles siguiendo el guión de entrevista.

El gran efecto positivo de las instrucciones y preguntas más ambiguas es que se fueron desarrollando temas que no hacían parte estricta del guión de la entrevista y que perfilamos en el análisis. Parte de los resultados se centraron en la exploración de los mismos usos.

De esta manera, esta triada metodológica multimodal nos ha permitido elaborar un conocimiento profundo sobre la cotidianidad laboral y perfilar los ejes de autonomía que se tejen alrededor de la rutina. El análisis temático de contenido cuenta con la flexibilidad necesaria para poder integrar, no sólo el material obtenido en el trabajo de campo, sino también cotejarlo con resultados de investigaciones previas y teoría relativa a cada categoría, cuando se les integra efectivamente.

\section{REFERENCIAS}

ALHOJAILAN, M. I. (2012, October): "Thematic analysis: a critical review ofits process and evaluation". Presented at the WEI International European Academic Conference Proceedings, Zagreb, Croatia.

BANKS, M. (2007): Using Visual Data in Qualitative Research, Londres, Sage.

BARTHES, R. (1999): La Cámara Lúcida: Nota Sobre La Fotografía, Barcelona, Paidós.

BOLTON, A., POLE, C., \& MIZEN, P. (2001): "Picture This: Researching Child Workers", Sociology, 35(2), pp. 501-518. http://doi.org/10.1017/ $\underline{\text { S0038038501000244 }}$

BONETTO, M. J. (2016): "El uso de la Fotografía en la investigación social”, Revista Latinoamericana de Metodología de la Investigación Social, 6(11), pp. 71-83.

CASTLEDEN, H., GARVIN, T., \& FIRST NATION, H. (2008): "Modifying Photovoice for community-based participatory Indigenous research", Social Science \& Medicine, 66(6), pp. 1393-1405. http://doi.org/10.1016/j.socscimed.2007.11.030

COLLIER, J. (1957): "Photography in Anthropology: A Report on Two Experiments", American Anthropologist, 59(5), pp. 843-859.

CORREDOR, F., TIRADO, F., \& ÍNIIGUEZ, L. (2010): “¿Bajo las riendas del teléfono móvil? Control social, normalización y resistencia”, Picologia \& Sociedade, 22(1), pp. 60-69. http://doi.org/10.1590/S0102-71822010000100008

COWDEN, S., \& SINGH, G. (2007): "The "User": Friend, foe or fetish?: A critical exploration of user involvement in health and social care", Critical Social Policy, 27(1), pp. 5-23. http://doi.org/10.1177/0261018307072205

DEEGAN, P. E., \& DRAKE, R. E. (2006). "Shared Decision Making and Medication Management in the Recovery Process", Psychiatr Serv, 57(11), pp. 1636-1639. http://doi.org/10.1176/appi.ps.57.11.1636

EPSTEIN, I., STEVENS, B., MCKEEVER, P., \& BARUCHEL, S. (2006): "Photo elicitation interview (PEI): Using photos to elicit children's perspectives", International Journal of Qualitative Methods, 5(3), pp. 1-9.

FABRA, M. L., \& DOMÈNECH, M. (2001): Hablar y escuchar: Relatos de profesor@ sy Estudiant@s, Barcelona, Paidós. 
GARCÍA-VILLAMISAR, D., WEHMAN, P., \& NAVARRO, M. (2002): "Changes in the quality of autistic people's life that work in supported and sheltered employment. A 5-year follow-up study", Journal of Vocational Rehabilitation, 17(4), pp. 309312.

GRBICH, C. (1999): Qualitative Research in Health, Londres, Sage.

GUASCH, O. (2002): Observación participante (2nd ed.), Madrid, Centro de Investigaciones Sociológicas.

HARPER, D. (2002): “Talking about pictures: a case for photo elicitation", Visual Studies, 17(1), pp. 13-26. http://doi.org/10.1080/14725860220137345

HODGETTS, D., RADLEY, A., CHAMBERLAIN, K., \& HODGETTS, A. (2007): "Health Inequalities and Homelessness: Considering Material, Spatial and Relational Dimensions", J Health Psychol, 12(5), pp. 709-725. http://doi. org/10.1177/1359105307080593

HUBERMAN, M., \& MILES, M. (2002). "Métodos para el manejo y análisis de datos", en C. Denman \& Haro (Eds.), Por los rincones. Antología de métodos cualitativos en la investigación social. Hermosillo, Sonora, México, Universidad de Guadalajara. pp. 253-289

HURWORTH, R., CLARK, E., MARTIN, J., \& THOMSEN, S. (2005): “The use of photointerviewing: Three examples from health evaluation and research", Evaluation Journal of Australasia, 4(1/2), pp. 52-62.

ÍÑIGUEZ RUEDA, L. (1999). "Investigación y evaluación cualitativa: bases teóricas y conceptuales", Atención Primaria, 23(8), pp. 496-502.

ÍÑIGUEZ, L. (2004). El debate sobre metodología cualitativa versus cuantitativa (Documento de trabajo), disponible en https://otredades.files.wordpress. com/2013/01/el-debate-sobre-metodologc3ada-cualitativa-versus-cuantitativa.pdf [consulta 6-7-2014].

ÍÑIGUEZ, L. (2006). "El análisis del discurso en las ciencias sociales: variedades, tradiciones y práctica", en L. Íñiguez (Ed.), “Análisis del discurso: manual para las ciencias sociales" ( $2^{\mathrm{a}}$ ed.), Barcelona, UOC, pp. 89-129.

JOHNSON, K. (2009, June): Personal and social transformation: considering LGBT lives (conferencia), Barcelona - UAB.

JOHNSON, K. (2012): "Visualising mental health with an LGBT community group", en P. Reavey (Ed.), Visual Methods in Psychology: Using and Interpreting Images in Qualitative Research, East Sussex, Routledge, pp. 173-190.

LABBO, L. D., EAKLE, A. J., \& MONTERO, M. K. (2002): "Digital language experience approach: Using digital photographs and software as a language experience approach innovation", Reading Online, 5(8), pp. 24-43.

LATOUR, B. (2001): La esperanza de Pandora: ensayos sobre la realidad de los estudios de la ciencia (T. Fernández Aúz, Trans.), Barcelona, Gedisa.

LOPEZ, E. D. S., ENG, E., RANDALL-DAVID, E., \& ROBINSON, N. (2005): "Quality-of-Life Concerns of African American Breast Cancer Survivors Within Rural North Carolina: Blending the Techniques of Photovoice and Grounded Theory”, Qual Health Res, 15(1), pp. 99-115. http://doi. org/10.1177/1049732304270766

MUÑ̃Z JUSTICIA, J. (2004): Análisis cualitativo de datos textuales con ATLAS.ti 5, Barcelona, Autor. 
PALlARÈS, S., GARAY, A., VÁZQUEZ, F., MUÑOZ, J., MARTÍNEZ, M., \& ÍÑIGUEZ, L. (2002): "Evaluación cualitativa del sistema de recogida de sangre en Cataluña”. Revista Española de Salud Pública, 76(5), pp. 437-450. http://doi. org/10.1590/S1135-57272002000500006

RADLEY, A., HODGETTS, D., \& CULLEN, A. (2005): "Visualizing homelessness: a study in photography and estrangement", Journal of Community \& Applied Social Psychology, 15(4), pp. 273-295. http://doi.org/10.1002/casp.825

RADLEY, A., \& TAYLOR, D. (2003): "Images of Recovery: A Photo-Elicitation Study on the Hospital Ward", Qual Health Res, 13(1), pp. 77-99. http://doi. org/10.1177/1049732302239412

REAL ACADEMIA ESPAÑOLA. (s/f): "Provocar", Diccionario de la Real Academia Española, Madrid, disponible en http://lema.rae.es/drae/?val=provocar [consulta 23-9-2014].

REAL ACADEMIA ESPAÑOLA. (2005): "Elicitar", Diccionario panhispánico de dudas, Madrid, disponible en http://lema.rae.es/dpd/srv/search?key=elicitar [consulta 23-9-2014].

ROSE, G. (2001): Visual Methodologies: An Introduction to the Interpretation of Visual Materials, London, Sage.

SENNETT, R. (2003): El Respeto: Sobre La Dignidad Del Hombre En Un Mundo De Desigualdad, Barcelona, Anagrama.

SENNETT, R. (2005): La Corrosión Del Carácter: Las Consecuencias Personales Del Trabajo En El Nuevo Capitalismo (5a ed), Barcelona, Anagrama.

SENNETT, R. (2009): El artesano, Barcelona, Anagrama.

SILVA RÍOS, C. E., \& BURGOS DÁVILA, C. J. (2011): "Tiempo mínimoconocimiento suficiente. La cuasi-etnografía sociotécnica en psicología social", Psicoperspectivas. Individuo Y Sociedad, 10(2). http://doi.org/10.5027/ psicoperspectivas-Vol10-Issue2-fulltext-146

SOTO RAMÍREZ, J. (2012): "Las imágenes y la sociedad (o las imágenes, la sociedad y su desciframiento)", Athenea Digital, 12(3), pp. 217-224. http://doi.org/10.5565/ rev/athenead/v12n3.1081

SUCHAR, C. S. (1997): "Grounding Visual Sociology Research in Shooting Scripts", Qualitative Sociology, 20(1), pp. 33-55. http://doi.org/10.1023/A:1024712230783

THOMPSON, N. C., HUNTER, E. E., MURRAY, L., NINCI, L., ROLFS, E. M., \& PALLIKKATHAYIL, L. (2008): “The Experience of Living With Chronic Mental Illness: A Photovoice Study", Perspectives in Psychiatric Care, 44(1), pp. 14-24. http://doi.org/10.1111/j.1744-6163.2008.00143.x

VÁZQUEZ, F. (1996): El análisis de contenido temático (Documento de trabajo, pp. 4770), Universitat Autónoma de Barcelona, Barcelona: Autor.

WANG, C. (1999): "Photovoice: a participatory action research strategy applied to women's health", Journal of Women's Health / the Official Publication of the Society for the Advancement of Women's Health Research, 8(2), pp. 185-192. http://doi.org/10.1089/jwh.1999.8.185

WANG, C., \& BURRIS, M. A. (1994): "Empowerment through Photo Novella: Portraits of Participation", Health Education \& Behavior, 21(2), pp. 171-186. http://doi. org/10.1177/109019819402100204 